\title{
Premature and severe cardiovascular disease in a Mexican male with markedly low high-density- lipoprotein-cholesterol levels and a mutation in the lecithin:cholesterol acyltransferase gene: A family study
}

\author{
ROSALINDA POSADAS-SÁNCHEZ ${ }^{1}$, CARLOS POSADAS-ROMERO ${ }^{1}$, WENDY ANGÉLICA OCAMPO-ARCOS ${ }^{1}$, \\ MARÍA TERESA VILLARREAL-MOLINA ${ }^{2}$, GILBERTO VARGAS-ALARCÓN ${ }^{3}$, ERIKA ANTÚNEZ-ARGÜELLES ${ }^{2}$, \\ ENRIQUE MENDOZA-PÉREZ ${ }^{1}$, GUILLERMO CARDOSO-SALDAÑA ${ }^{1}$, ROCÍO MARTÍNEZ-ALVARADO ${ }^{1}$, \\ AÍDA MEDINA-URRUTIA ${ }^{1}$ and ESTEBAN JORGE-GALARZA ${ }^{1}$ \\ ${ }^{1}$ Department of Endocrinology, National Institute of Cardiology 'Ignacio Chávez' (INCICH), Tlalpan, Mexico City 14080; \\ ${ }^{2}$ Laboratory of Genomics of Cardiovascular Disease, National Institute of Genomic Medicine (INMEGEN), Tlalpan, \\ Mexico City 14610; ${ }^{3}$ Department of Molecular Biology, National Institute of Cardiology 'Ignacio Chávez’ (INCICH), \\ Tlalpan, Mexico City 14080, Mexico
}

Received December 3, 2013; Accepted March 18, 2014

DOI: $10.3892 / \mathrm{ijmm} .2014 .1733$

\begin{abstract}
Epidemiological and clinical studies have shown that a low plasma high-density lipoprotein cholesterol (HDL-C) level is a strong predictor of cardiovascular disease (CVD). Lecithin:cholesterol acyltransferase (LCAT) is a key enzyme in the formation, maturation and function of HDL. Therefore impaired LCAT function may enhance atherosclerosis because of defective cholesterol transport. In this study, we examined a 34-year old LCAT-deficient patient and eight first-degree family members. There was a strong family history for CVD and type 2 diabetes mellitus (DM2). The proband was found homozygous for a previously reported LCAT gene mutation (Thr37Met). A sister and two sons of the proband were heterozygous for the same mutation. The proband had DM2 and showed severe multivessel coronary artery disease, corneal opacification and extremely low HDL-C levels. Large HDL particles were absent while small HDL particles were increased. The HDL of the patient had a reduced ability to promote cell cholesterol efflux, and the low-density lipoproteins (LDL) were more susceptible to oxidation. Among his family members, two heterozygotes and one non-carrier had early carotid or coronary atherosclerosis. In conclusion, as the increased LDL oxidability and structural and functional abnormalities of HDL particles have been reported in patients with obesity and diabetes, the results suggested that the adverse coronary risk profile, and not being
\end{abstract}

Correspondence to: Dr Carlos Posadas-Romero, Juan Badiano 1, Col Sección XVI, Tlalpan, Mexico City 14080, Mexico

E-mail: cposadasr@yahoo.com

Key words: low plasma high-density lipoprotein cholesterol, lecithin cholesterol acyltransferase deficiency, high-density lipoprotein function, coronary artery calcium, coronary heart disease
LCAT deficient, may be responsible for the CVD found in our proband, and for the early atherosclerosis observed in the two heterozygotes and in the wild-type family members.

\section{Introduction}

Plasma concentrations of high-density lipoprotein (HDL) cholesterol have been reported to have a strong and independent inverse association with risk of coronary artery disease (CAD) events (1). It has been shown that $30-55 \%$ of high-density lipoprotein cholesterol (HDL-C) concentration variability is determined by genetic factors (2). Apolipoprotein AI (apoA-I) and lecithin:cholesterol acyltransferase (LCAT) gene mutations result in extremely low HDL-C levels (3). LCAT, a plasma enzyme, esterifies free cholesterol primarily at the surface of the HDL particle, has a central role in HDL formation and maturation (4), and in the intravascular stage of reverse cholesterol transport (RCT), the major mechanism by which HDL modulates the development and progression of atherosclerosis. In addition to its cholesterol-esterifying activity, LCAT seems to have a scavenger effect towards low-density lipoprotein (LDL) oxidation products (5). The human LCAT gene encompasses $4.2 \mathrm{~kb}$ and is localized in the q21-22 region of chromosome 16 (6). Based on strict biochemical criteria, homozygotes or compound heterozygotes for these mutations are classified into the familial LCAT deficiency (FLD) and fish-eye disease (FED) syndromes (7). In FLD, LCAT plasma is absent or completely lacks catalytic activity, while in FED, the LCAT mutant lacks activity on HDL ( $\alpha$-LCAT activity) but esterifies cholesterol bound to apolipoprotein B-containing lipoproteins ( $\beta$-LCAT activity). All reported FLD and FED cases have massive corneal opacity and markedly reduced plasma HDL levels (3), although the prevalence of CAD may be higher in FED than in FLD patients (6). Heterozygous carriers of LCAT mutations may have either low (8-9) or normal (8) plasma HDL-C levels without premature CAD. At present, 
$\sim 60$ isolated cases and 70 small families with partial or complete LCAT deficiency with 86 different LCAT gene mutations have been described (10). Atherosclerosis susceptibility has been extensively investigated in FED and FLD patients (10). Studies assessing the association between the inherited LCAT functional defect and CAD have been limited to measurements of only some variables, such as the HDL subclasses (11-12) size (9) and function (13-14), apoA-I and apoA-II plasma concentrations (9), inflammation (15), and carotid intima-media-thickness (cIMT) (15-16). This study aimed to provide more information on the LCAT-deficient state and its association with CAD by describing LDL susceptibility to oxidation in addition to the above-mentioned variables, in a LCAT-deficient patient with severe premature CAD and his nuclear family.

\section{Materials and methods}

Subjects. The proband was a 34 year-old male, with family and personal history of type 2 diabetes mellitus (DM2), obesity, hypertension and premature CAD. His cardiovascular history included unstable angina, coronary bypass surgery, intracoronary placement of five stents, stent restenosis and myocardial infarction. He had bilateral corneal opacity (Fig. 1) without retinopathy, with no signs of anemia and normal renal function. First-degree relatives of the proband were invited to participate in the study and all subjects provided signed informed consent. The study complies with the Declaration of Helsinki and was approved by the Ethics Committee of the National Institute of Cardiology 'Ignacio Chávez' (INCICH).

Biochemical measurements. Blood samples were collected after a 10 - to 12-h fast. Plasma glucose, total cholesterol, triglycerides (TG), and HDL-C were measured using standard enzymatic procedures in a Hitachi 902 analyzer (Hitachi Ltd., Tokyo, Japan) and LDL cholesterol levels were estimated. In our laboratory, accuracy and precision are periodically evaluated by the Centers for Disease Control and Prevention (Atlanta, GA, USA). Total high-sensitivity C-reactive protein (hs-CRP), apolipoprotein B (apoB), and apoA-I levels were determined by immunonephelometry on a BN ProSpec nephelometer (Dade Behring, Marburg, Germany), with an interassay coefficient of variation of $<6 \%$. Plasma insulin concentrations were determined by a radioimmunometric assay (Coat-A-Count; Diagnostic Products, Los Angeles, CA, USA).

Total HDL was isolated from the plasma by sequential ultracentrifugation in a density of $1.21 \mathrm{~g} / \mathrm{ml}$ at $4^{\circ} \mathrm{C}$ in a Beckman TL-100 ultracentrifuge. The resulting total HDL was dialyzed against phosphate buffer ( $\mathrm{pH} 7.4$ ), loaded into native 4-25\% polyacrylamide electrophoresis gels and analyzed by automated densitometry, as previously described (17). The coefficient of variation for each subclass was $<10 \%$.

LCAT activity and the cholesterol esterification rate (CER) were measured according to the methods of Chen and Albers (18). LDL susceptibility to in vitro oxidation was determined by a modification of the method of Esterbauer (19), constructing an oxidation kinetics curve to calculate the lag phase (LP). Intra- and intervariation coefficients for these measurements were 2.94 and $5.77 \%$, respectively. Serum PON1 activity was determined photometrically (Beckman DU650, Fullerton, CA, USA) using paraoxon (Sigma-Aldrich D9286;

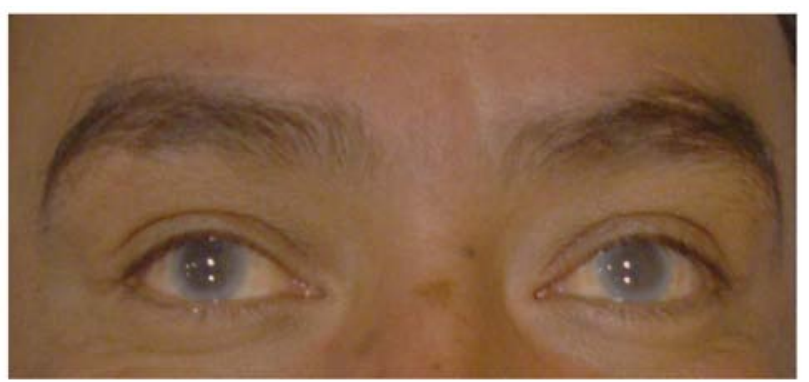

Figure 1. Corneal opacity.

St. Louis, MO, USA) as a substrate (20). The capacity of total isolated HDL to promote cell cholesterol efflux was tested for each individual. cAMP-stimulated J774 murine macrophages and Fu5AH hepatoma cells were used to assess ABCA1 and SR-BI-mediated cholesterol efflux, respectively, following the procedure described by de la Llera-Moya et al (21-22), with slight modifications. Briefly, total isolated HDL fractions as estimated by phospholipids (100 $\mu \mathrm{g}$ of phospholipids/ml) were incubated with 1,2-3H cholesterol labeled Fu5AH or J774 cells at $37^{\circ} \mathrm{C}$ for $4 \mathrm{~h}$. The percentage of cholesterol efflux was calculated comparing radioactivity measurements in the medium and cells. All the determinations were performed in triplicate. As an internal control, isolated total HDL was included in each plate. Intra- and interassay coefficient variations for this method were 4.9 and $8.1 \%$, respectively.

Radiological studies. Carotid intima-media-thickness measurements were performed using a MicroMaxx ultrasound device (SonoSite, Inc., Bothell, WA, USA), equipped with a 7.0-14 MHz linear-array wideband transducer to obtain B-mode ultrasound images (23). The common carotid artery, bulb and internal carotid artery were bilaterally scanned over a length of $10 \mathrm{~mm}$. The mean combined outcome of the six segments was reported. Computed tomography of the chest and abdomen were performed using a 64-channel multidetector helical computed tomography system (Somatom Sensation, Siemens, Munich, Germany) and interpreted by experienced radiologists. Scans were read to assess and quantify coronary artery calcification (CAC) score using the Agatston method (24). Subclinical atherosclerosis (SA) was defined as the presence of coronary calcium (CAC score $>0$ ).

LCAT gene sequencing. DNA was isolated from peripheral venous blood by a modified salting out method (25). The amplification mix $(50 \mu \mathrm{l})$ included 150-300 ng of genomic DNA, 1 unit of Taq DNA polymerase (Promega, Madison, WI, USA) in 1X PCR buffer, $5 \mathrm{mM} \mathrm{MgCl}_{2}$ and $0.4 \mathrm{mM}$ of each dNTP. Other conditions for the LCAT gene amplification are detailed in Table I. PCR products were purified using the QIAquick PCR purification kit (Qiagen, Inc., Chatsworth, CA, USA), and purification products were directly sequenced on an ABI Prism 3100 Sequencer according to the manufacturer's instructions.

\section{Results}

Mutational analysis. The sequence of all six exons of the LCAT gene revealed the proband was homozygous for a 
Table I. Conditions for the LCAT gene amplification.

\begin{tabular}{|c|c|c|c|c|c|c|c|}
\hline Exon & $\begin{array}{l}\text { Primer } \\
\text { sequence }\end{array}$ & $\begin{array}{c}\text { Primer } \\
\text { concentration } \\
\mu \mathrm{M}\end{array}$ & $\begin{array}{l}\mathrm{DMSO} \\
(\%)\end{array}$ & $\begin{array}{c}\text { Initial } \\
\text { denaturation } \\
\text { step }\end{array}$ & $\begin{array}{l}\text { No. of } \\
\text { cycles }\end{array}$ & Cycle conditions & $\begin{array}{l}\text { Extension } \\
\text { conditions }\end{array}$ \\
\hline 1 & $\begin{array}{l}\text { 5'-CGGCAATCTCTGGCCACAACC-3' (F) } \\
\text { 5'-GGCTTATGCAGGGCAGAAGG-3' (R) }\end{array}$ & 0.2 & 10 & $94^{\circ} \mathrm{C}$ for $5 \mathrm{~min}$ & 30 & $\begin{array}{c}94^{\circ} \mathrm{C} \text { for } 30 \mathrm{sec}, \\
63^{\circ} \mathrm{C} \text { for } 30 \mathrm{sec}, \\
72^{\circ} \mathrm{C} \text { for } 1 \mathrm{~min} 16 \mathrm{sec}\end{array}$ & $72^{\circ} \mathrm{C}, 10 \mathrm{~min}$ \\
\hline $2+3$ & $\begin{array}{l}\text { 5'-GGGTCACGGGGGGAATCCAG-3' (F) } \\
\text { 5'-GGCTTGGGCCATGCCTGCTG-3' (R) }\end{array}$ & 0.3 & 10 & $94^{\circ} \mathrm{C}$ for $5 \mathrm{~min}$ & 35 & $\begin{array}{l}94^{\circ} \mathrm{C} \text { for } 20 \mathrm{sec}, \\
64^{\circ} \mathrm{C} \text { for } 30 \mathrm{sec}, \\
72^{\circ} \mathrm{C} \text { for } 40 \mathrm{sec}\end{array}$ & $72^{\circ} \mathrm{C}, 10 \mathrm{~min}$ \\
\hline $4+5$ & $\begin{array}{l}\text { 5'-GGCTCCAGGCCTGGGTGCTG-3' (F) } \\
\text { 5'-GATAGCACCCCTAGAGGCCACTG-3' (R) }\end{array}$ & 0.4 & 20 & $94^{\circ} \mathrm{C}$ for $5 \mathrm{~min}$ & 35 & $\begin{array}{l}94^{\circ} \mathrm{C} \text { for } 30 \mathrm{sec}, \\
64^{\circ} \mathrm{C} \text { for } 45 \mathrm{sec}, \\
72^{\circ} \mathrm{C} \text { for } 30 \mathrm{sec}\end{array}$ & $72^{\circ} \mathrm{C}, 10 \mathrm{~min}$ \\
\hline 6 & $\begin{array}{l}\text { 5'-TGAGCCTACACTCAGCAGGTTGTG-3' (F) } \\
\text { 5'-CCCATCTTGCCTCACTGCACACA-3' (R) }\end{array}$ & 0.3 & 7.5 & $94^{\circ} \mathrm{C}$ for $5 \mathrm{~min}$ & 35 & $\begin{array}{l}94^{\circ} \mathrm{C} \text { for } 30 \mathrm{sec}, \\
61^{\circ} \mathrm{C} \text { for } 45 \mathrm{sec}, \\
72^{\circ} \mathrm{C} \text { for } 45 \mathrm{sec}\end{array}$ & $72^{\circ} \mathrm{C}, 10 \mathrm{~min}$ \\
\hline
\end{tabular}

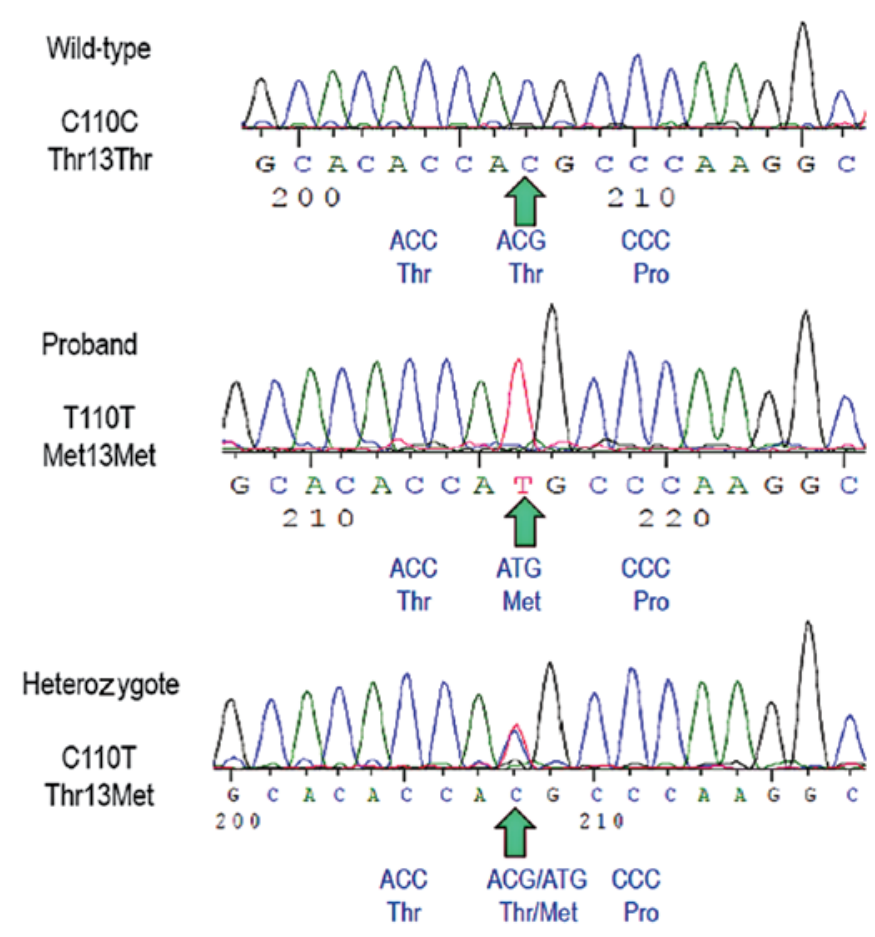

Figure 2. Electropherograms showing the lecithin: cholesterol acyltransferase (LCAT) gene mutation identified in exon 1: an individual with the wild-type genotype (upper panel), the proband (middle panel) and a heterozygous individual (lower panel). Arrows indicate the site of the mutation.

c. $110 \mathrm{C}>\mathrm{T}$ transition in exon 1 , a previously described mutation (Fig. 2) (26). The predicted translation of the mutant allele resulted in a missense non-conservative amino acid substitution of threonine for methionine at position 37 of the LCAT protein (Thr37Met). No other sequence variations were identified. The segregation of the mutant allele in this family is shown in Fig. 3. Two sisters (II-1 and II-3), two brothers (II-4 and II-5) and the daughter (III-2) of the proband were found to have wild-type genotypes, while one of the probands sisters (II-7) and his two sons (III-3- and III-4) were found to be heterozygous for the Thr37Met mutation.

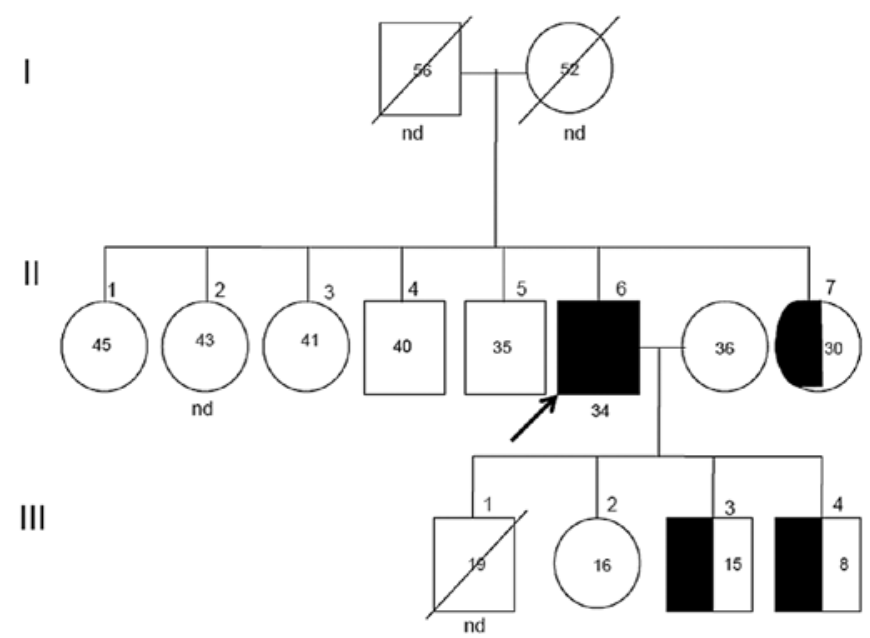

Figure 3. Family pedigree. The proband is homozygous for the mutation. Individuals heterozygous for the Thr13Met mutations are presented with half-filled shaded areas.

Biochemical analysis. HDL-C levels were markedly low in the proband $(2 \mathrm{mg} / \mathrm{dl})$, very low in all the heterozygous subjects (16-18 $\mathrm{mg} / \mathrm{dl})$ and low in non-carriers of the mutation as compared to a group of previously reported healthy male subjects (Table II) (27). It should be noted that all but one of the the proband's siblings had HDL-C levels $<40 \mathrm{mg} / \mathrm{dl}$, commonly associated with high TG levels ( $>150 \mathrm{mg} / \mathrm{dl})$. Compared with insulin and hs-CRP levels observed in healthy control subjects, several family members had increased insulin and hs-CRP $(>2.0 \mathrm{mg} / \mathrm{dl})$ levels. All the individuals with the exception of the proband's daughter (III-2) were overweight or obese, which may explain the increased levels of TG, insulin and hs-CRP. The proband and one of his sisters (II-3) had abnormal fasting glucose, and one of his brothers (II-4) had DM2. As expected, LCAT activity was lowest in the proband, $(2.1 \mathrm{nmol} / \mathrm{ml} / \mathrm{h})$, followed by the heterozygous subjects and individuals with wild-type genotypes. The proband also showed lower CER values. LDL susceptibility to oxidation analysis in vitro revealed that the LP was $70 \%$ shorter in the proband as compared to the 
Table II. Clinical and laboratory data of patient, family members and healthy subjects.

\begin{tabular}{|c|c|c|c|c|c|c|c|c|c|c|}
\hline \multirow[b]{2}{*}{ ID subject } & \multicolumn{9}{|c|}{ Proband } & \multirow{2}{*}{$\begin{array}{c}\text { Healthy } \\
\text { subjects } \\
\text { n=20 }\end{array}$} \\
\hline & $\mathrm{II}-1$ & II-3 & II-4 & II-5 & II-6 & II-7 & III-2 & III-3 & III-4 & \\
\hline Genotype & $\mathrm{CC}$ & $\mathrm{CC}$ & $\mathrm{CC}$ & $\mathrm{CC}$ & TT & $\mathrm{CT}$ & $\mathrm{CC}$ & $\mathrm{CT}$ & $\mathrm{CT}$ & - \\
\hline Age (years) & 45 & 41 & 40 & 35 & 34 & 30 & 16 & 15 & 8 & $53 \pm 8.5$ \\
\hline BMI $\left(\mathrm{kg} / \mathrm{m}^{2}\right)$ & 39 & 33 & 25 & 31 & 28 & 33 & 23 & 25 & 27 & $26 \pm 2.5$ \\
\hline Corneal opacity & - & - & - & - & + & - & - & - & - & - \\
\hline Presence of diabetes & - & - & + & - & + & - & - & - & - & - \\
\hline $\mathrm{TC}(\mathrm{mg} / \mathrm{dl})$ & 148 & 159 & 210 & 157 & 141 & 169 & 157 & 174 & 153 & $183 \pm 33$ \\
\hline HDL-C (mg/dl) & 32 & 30 & 51 & 34 & 2 & 16 & 42 & 18 & 17 & $59 \pm 18$ \\
\hline LDL-C (mg/dl) & 100 & 92 & 133 & 93 & 43 & 127 & 103 & 108 & 95 & $108 \pm 30$ \\
\hline $\mathrm{TG}(\mathrm{mg} / \mathrm{dl})$ & 98 & 233 & 156 & 186 & 597 & 161 & 73 & 297 & 255 & $100 \pm 27$ \\
\hline Apo A-I (mg/dl) & 116 & 115 & 163 & 140 & 45 & 76 & 126 & 91 & 95 & $167 \pm 38$ \\
\hline Apo B (mg/dl) & 94 & 92 & 146 & 92 & 172 & 121 & 100 & 109 & 103 & $82 \pm 17$ \\
\hline Glucose (mg/dl) & 92 & 106 & 181 & 91 & 104 & 85 & 79 & 90 & 84 & $87 \pm 6$ \\
\hline Insulin $(\mu \mathrm{U} / \mathrm{ml})$ & 12 & 11 & nd & 10 & 4.9 & 15 & 1.2 & 10 & 7.3 & $9 \pm 6$ \\
\hline hs-CRP (mg/l) & 2.3 & 5.7 & 0.65 & 3.4 & 8.4 & 4.0 & 0.5 & 1.4 & 4.8 & $1.2 \pm 0.8$ \\
\hline LCAT activity $(\mathrm{nmol} / \mathrm{ml} / \mathrm{h})$ & 15 & 12 & nd & 12 & 2.1 & 8 & 12 & 9 & 10 & - \\
\hline CER (nmol/ml/h) & 26 & 26 & nd & 26 & 9 & 17 & 18 & 24 & 21 & - \\
\hline $\mathrm{LP}(\min )$ & 36 & 40 & 33 & 43 & 19 & 47 & 32 & 37 & 46 & $62 \pm 5$ \\
\hline
\end{tabular}

a'Data from Posadas-Sánchez et al (27). BMI, body mass index; TC, total cholesterol; HDL-C, high-density lipoprotein cholesterol; LDL-C, low-density lipoprotein cholesterol; TG, triglycerides; Apo, apolipoprotein; hs-CRP, high sensitivity C-reactive protein; LCAT, lecithin cholesterol acyltransferase; CER, cholesterol esterification rate; $\mathrm{LP}$, lag phase. In healthy subjects values are means $\pm \mathrm{SD}$.

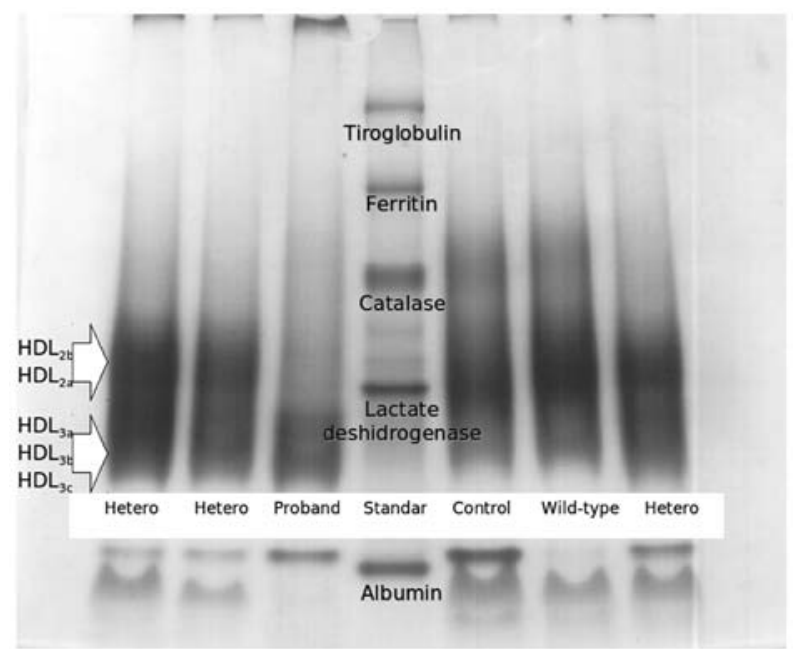

Figure 4. Polyacrylamide gradient gel electrophoresis of total isolated high-density lipoprotein (HDL) from the proband, three heterozygous subjects and an individual without the mutation.

mean LP estimated in healthy controls, indicating increased LDL oxidability, whereas LP duration was not different in the heterozygous and family non-mutation carriers, but was shorter in family members as compared to the healthy controls.
HDL subclasses and cholesterol efflux. Table III shows the distribution of HDL subclasses for all the participants. The proband showed an absence of large HDL, while heterozygous mutation carriers showed reduced proportions of large HDL levels $\left(\mathrm{HDL}_{2 \mathrm{~b}}\right.$ and $\left.\mathrm{HDL}_{2 \mathrm{a}}\right)$ and increased small HDL $\left(\mathrm{HDL}_{3 \mathrm{c}}\right)$ as compared to healthy subjects. Fig. 4 shows an electrophoretogram of HDL, where the proband showed an absence of large subclasses and higher proportion of small HDL subclasses. Compared with healthy control subjects, the HDL size was lower in the heterozygous subjects and proband had the smallest HDL size. PON1 activity was low in the proband and in three siblings not carrying the mutation (II-1, II-4, II-5), while the heterozygous family members showed normal values. cAMP-stimulated J774 murine macrophages and Fu5AH hepatoma cells were used to assess the ABCA1 and SR-BI-mediated cholesterol efflux capacity from total isolated HDL of all the participants. While ABCA-1 mediated cholesterol efflux to total isolated HDL was similar among all subjects independently of the presence of LCAT mutation, SRB1-mediated cholesterol efflux from the proband was less than half of that observed in healthy controls and heterozygous participants (Table III).

Intima media thickness results. As shown in Table IV, cIMT was above the 50th percentile for age and gender in the 
Table III. HDL subclass distribution, paraoxonase activity and cholesterol efflux of patient, family members and healthy subjects.

\begin{tabular}{|c|c|c|c|c|c|c|c|c|c|c|}
\hline \multirow[b]{2}{*}{ ID subject } & \multicolumn{9}{|c|}{ Proband } & \multirow{2}{*}{$\begin{array}{l}\text { Healthy } \\
\text { subjects }^{\mathrm{a}} \\
\mathrm{n}=20\end{array}$} \\
\hline & II-1 & II-3 & II-4 & II-5 & II-6 & II-7 & III-2 & III-3 & III-4 & \\
\hline Genotype & $\mathrm{CC}$ & $\mathrm{CC}$ & $\mathrm{CC}$ & $\mathrm{CC}$ & TT & $\mathrm{CT}$ & $\mathrm{CC}$ & $\mathrm{CT}$ & $\mathrm{CT}$ & - \\
\hline \multicolumn{11}{|l|}{ HDL subclass distribution } \\
\hline $\mathrm{HDL}_{2 \mathrm{a}}, \%$ & 17 & 22 & 18 & 17 & 0 & 14 & 20 & 13 & 13 & $21 \pm 2.9$ \\
\hline $\mathrm{HDL}_{2 \mathrm{~b}}, \%$ & 9 & 13 & 12 & 10 & 0 & 10 & 14 & 10 & 7 & $16 \pm 4.6$ \\
\hline $\mathrm{HDL}_{2}, \%$ & 26 & 35 & 31 & 26 & 0 & 24 & 34 & 24 & 20 & $37 \pm 7.2$ \\
\hline $\mathrm{HDL}_{3 \mathrm{a}}, \%$ & 29 & 31 & 25 & 30 & 15 & 28 & 28 & 27 & 27 & $24 \pm 2.2$ \\
\hline $\mathrm{HDL}_{3 \mathrm{~b}}, \%$ & 26 & 21 & 23 & 25 & 30 & 25 & 23 & 25 & 26 & $24 \pm 2.8$ \\
\hline $\mathrm{HDL}_{3 \mathrm{c}}, \%$ & 19 & 13 & 22 & 18 & 55 & 23 & 15 & 25 & 27 & $15 \pm 4.9$ \\
\hline $\mathrm{HDL}_{3}, \%$ & 74 & 65 & 69 & 74 & 100 & 76 & 66 & 76 & 80 & $63 \pm 7.2$ \\
\hline HDL size (nm) & 8.6 & 8.8 & 8.7 & 8.6 & 7.8 & 8.5 & 8.8 & 8.5 & 8.4 & $9 \pm 0.2$ \\
\hline PON1 activity $(\mathrm{nmol} / \mathrm{ml} / \mathrm{min})$ & 77 & 321 & 33 & 98 & 75 & 328 & 341 & 296 & 328 & $338 \pm 112^{b}$ \\
\hline \multicolumn{11}{|c|}{ Cholesterol efflux to total isolated HDL } \\
\hline ABCA1-mediated (\%) & 3.2 & 3.8 & 3.5 & 2.6 & 2.7 & 3.1 & 2.6 & 3.9 & 3.5 & - \\
\hline SRB1-mediated (\%) & 4 & 6 & 7 & 8 & 2.5 & 7 & 7 & 5 & 7 & $5.6 \pm 1.4$ \\
\hline
\end{tabular}

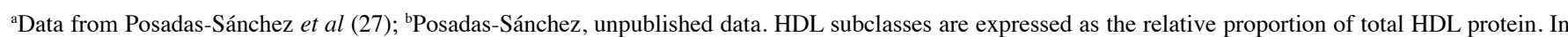
healthy subjects values are means \pm SD. PON, paraoxonase.

Table IV. Coronary artery calcium, carotid intima-media-thickness and plaque of patient and his family members.

\begin{tabular}{lcccccccccc}
\hline & \multicolumn{7}{c}{ Proband } \\
\cline { 2 - 8 } ID subject & II-1 & II-3 & II-4 & II-5 & II-6 & II-7 & III-2 & III-3 & III-4 \\
\hline Genotype & CC & CC & CC & CC & TT & CT & CC & CT & CT \\
Coronary artery calcium (Agatston) & 0 & 0 & 141.5 & 0 & - & - & - & 2.9 & 0 \\
Carotid intimal media thickness (mm) & 0.65 & 0.58 & $0.68^{\mathrm{a}}$ & 0.63 & $0.78^{\mathrm{a}}$ & - & - & 0.43 & $0.49^{\mathrm{a}}$ \\
Carotid plaque & - & - & + & - & + & - & - & - \\
\hline
\end{tabular}

avalue above percentile 50-75 for age and gender [Stein et al (23)].

proband, in one of his heterozygous sons (III-4) and in one of his wild-type brothers (II-4), while carotid plaque was present only in the proband and in the wild-type brother. Calcified coronary artery $(\mathrm{CAC}>0)$, as a measure of subclinical atherosclerosis, was present in brother II-4 and in one of his sons (III-3) (Table IV).

\section{Discussion}

The present study assessed increased LDL oxidability and structural and functional abnormalities of HDL particles from the second youngest LCAT-deficient patient with markedly severe premature CAD studied thus far. The case was a 34-year-old man with an adverse cardiovascular risk profile, multivessel coronary disease, corneal opacity, very low HDL-C levels, normal renal function, and no signs of anemia. Although his parents were apparently not consanguineous, he was found to be homozygous for a previously described mutation in the LCAT gene (c.110T in exon 1) (26). Since CER and LCAT activity were detectable in the proband, he could not be classified as either FLD or FED according to current biochemical criteria $(7,28)$. LCAT is a critical enzyme in HDL metabolism. Individuals with loss-of-function mutations in the two alleles show an inability to form mature HDL particles with a cholesteryl ester core and rapid catabolism of circulating apoA-I and apoA-II (29). As a result, these patients have very low HDL-C levels and several physicochemical and functional HDL abnormalities.

In a large series of LCAT-deficient subjects, Calabresi et al (12) demonstrated that HDL particle size distribution in carriers of two mutant LCAT alleles is characterized by the lack of particles in the $\mathrm{HDL}_{2}$ size range and the presence of a single $\mathrm{HDL}_{3}$ subpopulation of particles, with an average size smaller than that of control $\mathrm{HDL}_{3}$. This is in agreement with our findings of reduced large HDL and increased small HDL subclasses, and lower HDL size in the homozygous and the 
heterozygous subjects when compared with healthy control subjects. PON1 activity is associated with HDL in human serum (30), and inhibits the accumulation of oxidized lipids (31), thus preventing oxidative modifications of LDL and the conversion of this lipoprotein into particles with atherogenic properties (32). While preserved PON1 activity has been found in HDL-deficient states $(14,33,34)$, in our patient, PON1 activity was reduced $78 \%$ compared with the healthy control subjects (Table III). The interindividual variability in serum PON1 activity seems to be regulated by genetic SNPs, environmental (tobacco, alcohol, fatty acids) (35) and biochemical (HDL-C and total cholesterol levels) (36) factors that may increase or reduce PON1 activity, which may explain the low activity found in the proband and some of the family members.

While ABCA1-mediated cholesterol efflux to total isolated HDL was preserved in mutation carriers (Table III), SRB1-mediated efflux to total isolated HDL was reduced $\sim 50 \%$ in the proband relative to the efflux of the healthy control group. These results are in line with a previous study reporting that serum from LCAT gene mutation carriers is similar to control serum in the ability to promote cholesterol efflux via ABCA1, but less efficient than serum from control subjects in promoting SRB1-mediated cell cholesterol efflux (37).

LDL are heterogeneous in size, density, lipid composition, and possibly atherogenicity. Compared to LDL from control subjects, LDL particles from carriers of two mutant LCAT alleles are smaller (12), have an abnormal composition (poor in cholesteryl esters and rich in TG and phospholipids) (38), and are more easily oxidized. Oxidation results in a cytotoxic LDL with pro-inflammatory and atherogenic properties. In addition to abnormalities in HDL-related characteristics, LDL particles from the proband showed a $70 \%$ reduction in the LP compared to the average LP of normal LDL from healthy subjects, indicating that despite his low LDL-C levels (43 mg/dl), these lipoproteins were highly susceptible to oxidation. Reduced PON1 and LCAT activities are likely to cause lower scavenger activity towards LDL oxidation products $(13,31)$, which together with a potential abnormal LDL composition, may explain the high LDL oxidability found in this patient.

Plasma concentrations of HDL-C have been shown to have a strong and independent inverse association with risk of CAD (1). Nevertheless, some monogenic disorders with extremely low HDL-C levels, such as the apoA-IMilano mutation, Tangier disease and LCAT deficiency, are not generally associated with accelerated atherosclerosis. More than 86 defects in LCAT gene have been identified (10), and for several decades conflicting findings on the association of LCAT deficiency with atherosclerosis have been reported in humans and experimental animals $(7,39)$. Thus, some $(15,40)$ but not all studies $(16)$, have found that reduced LCAT activity is associated with increased cIMT and with the presence of CAD (10). A recent study reported that compared with 80 matched healthy controls, 12 individuals with two loss-of-function LCAT mutations and 28 heterozygous carriers with one mutation did not have increased cIMT as compared to 80 matched healthy controls, and instead there was a strong suggestion for a gene dose-dependent reduction in cIMT (16). These findings suggest that LCAT deficiency is not associated with increased cardiovascular risk. In the present study, the proband had severe and premature CAD, HDL abnormalities including very low HDL-C and apoA-I levels, absence of large HDL, increased small HDL, smaller HDL size, reduced PON1 activity, low SRB1-mediated cholesterol efflux, increased LDL susceptibility to oxidation, as well as increased TG, apoB and hsCRP levels. All these abnormalities have been associated with increased CAD risk $(1,3,27-28,41)$.

However, these metabolic alterations may also occur in overweight patients with DM2, hypertension, and CAD $(27,42)$, that were present in this patient, and could have opposed the antiatherogenic effect of low circulating levels of HDL previously described in other LCAT-deficient patients $(5,13,37)$.

In conclusion, these findings suggest that the adverse coronary risk profile and not the LCAT defect may be responsible for the CAD found in our proband, and the early atherosclerosis observed in the two heterozygotes and in the wild-type family members.

\section{Acknowledgements}

We would like to thank all family members investigated whose enthusiasm and helpfulness enabled us to perform this study. We also acknowledge Nélyda G. González-Lara for technical assistance.

\section{References}

1. Gotto AM Jr and Brinton EA: Assessing low levels of highdensity lipoprotein cholesterol as a risk factor in coronary heart disease: a working group report and update. J Am Coll Cardiol 43: 717-724, 2004.

2. Breslow JL: Familial disorders of high density lipoprotein metabolism. In: The Metabolic and Molecular Bases of Inherited Disease. Scriver CR, Beaudet AL, Sly WS and Valle D (eds). 7th editon. McGraw-Hill Publishing, New York, pp2031-2052, 1995.

3. Assmann G, von Eckardstein A and Funke H: High density lipoproteins, reverse transport of cholesterol, and coronary artery disease. Insights from mutations. Circulation 87 (Suppl 4): III28-III34, 1993.

4. Glomset JA: The plasma lecithins:cholesterol acyltransferase reaction. J Lipid Res 9: 155-167, 1968.

5. Howlader ZH, Kamiyama S, Shirakawa H, et al: Detoxification of oxidized LDL by transferring its oxidation product(s) to lecithin:cholesterol acyltransferase. Biochim Biophys Res Commun 291: 758-763, 2002.

6. Jonas A: Lecithin cholesterol acyltransferase. Biochim Biophys Acta 1529: 245-256, 2000.

7. Kuivenhoven JA, Pritchard H, Hill J, et al: The molecular pathology of lecithin: cholesterol acyltransferase (LCAT) deficiency syndromes. J Lipid Res 38: 191-205, 1997.

8. Frohlich J, McLeod R, Pritchard PH, et al: Plasma lipoprotein abnormalities in heterozygotes for familial lecithin: cholesterol acyltransferase deficiency. Metabolism 37: 3-8, 1988.

9. Kasid A, Rhyne J, Zeller K, et al: A novel TC deletion resulting in Pro(260)-Stop in the human LCAT gene is associated with a dominant effect on HDL-cholesterol. Atherosclerosis 156: 127-132, 2001.

10. Kunnen S and Van Eck M: Lecithin:cholesterol acyltransferase: old friend or foe in atherosclerosis? J Lipid Res 53: 1783-1799, 2012.

11. Asztalos BF, Schaefer EJ, Horvath KV, et al: Role of LCAT in HDL remodeling: investigation of LCAT deficiency states. J Lipid Res 48: 592-599, 2007.

12. Calabresi L, Pisciotta L, Costantin A, et al: The molecular basis of lecithin:cholesterol acyltransferase deficiency syndromes: a comprehensive study of molecular and biochemical findings in 13 unrelated Italian families. Arterioscler Thromb Vasc Biol 25: 1972-1978, 2005.

13. Charlton-Menys V, Pisciotta L, Durrington PN, et al: Molecular characterization of two patients with severe LCAT deficiency. Nephrol Dial Transplant 22: 2379-2382, 2007. 
14. Bérard AM, Clerc M, Brewer B Jr and Santamarina-Fojo S: A normal rate of cellular cholesterol removal can be mediated by plasma from a patient with familial lecithin-cholesterol acyltransferase (LCAT) deficiency. Clin Chim Acta 314: 131-139, 2001.

15. Hovingh GK, Hutten BA, Holleboom AG, et al: Compromised LCAT function is associated with increased atherosclerosis. Circulation 112: 879-884, 2005.

16. Calabresi L, Baldassarre D, Castelnuovo S, et al: Functional lecithin: cholesterol acyltransferase is not required for efficient atheroprotection in humans. Circulation 120: 628-635, 2009.

17. Medina-Urrutia A, Juarez-Rojas JG, Martínez-Alvarado R, et al: High-density lipoprotein subclasses distribution and composition in Mexican adolescents with low HDL cholesterol and/or high triglyceride concentrations, and its association with insulin and C-reactive protein. Atherosclerosis 201: 392-397, 2008.

18. Chen $\mathrm{CH}$ and Albers JJ: Characterization of proteoliposomes containing apoprotein A-I: a new substrate for the measurement of lecithin: cholesterol acyltransferase activity. J Lipid Res 23: 680-691, 1982

19. Posadas-Sánchez R, Posadas-Romero C, Zamora-González J et al: LDL size and susceptibility to oxidation in experimental nephrosis. Mol Cell Biochem 220: 61-68, 2001.

20. Eckerson HW, Wyte CM, LA and la Du BN: The human serum paraoxonase/arylesterase polymorphism. Am J Hum Genet 35: $1126-1138,1983$.

21. De la Llera-Moya M, Atger V, Paul JL, et al: A cell system for screening human serum for ability to promote cellular cholesterol efflux. Relations between serum components and efflux, esterification, and transfer. Arterioscler Thromb Vasc Biol 14: 1056-1065, 1994.

22. De la Llera-Moya M, Drazul-Schrader D, Asztalos BF, et al: The ability to promote efflux via ABCA1 determines the capacity of serum specimens with similar high-density lipoprotein cholesterol to remove cholesterol from macrophages. Arterioscler Thromb Vasc Biol 30: 796-801, 2010.

23. Stein JH, Korcarz CE, Hurst RT, et al; American Society of Echocardiography Carotid Intima-Media Thickness Task Force. Use of carotid ultrasound to identify subclinical vascular disease and evaluate cardiovascular disease risk: a consensus statement from the American Society of Echocardiography Carotid Intima-Media Thickness Task Force. Endorsed by the Society for Vascular Medicine. J Am Soc Echocardiogr 21: 93-111, 2008

24. Mautner GC, Mautner SL, Froehlich J, et al: Coronary artery calcification: assessment with electron beam CT and histomorphometric correlation. Radiology 192: 619-623, 1994.

25. Miller SA, Dykes DD and Polesky HF: A simple salting out procedure for extracting DNA from human nucleated cells. Nucleic Acids Res 16: 1215, 1988.

26. Argyropoulos G, Jenkins A, Klein RL, et al: Transmission of two novel mutations in a pedigree with familial lecithin:cholesterol acyltransferase deficiency: structure-function relationships and studies in a compound heterozygous proband. J Lipid Res 39 1870-1876, 1998.

27. Posadas-Sánchez R, Posadas-Romero C, Mendoza-Pérez E, et al: Cholesterol efflux and metabolic abnormalities associated with low high-density-lipoprotein-cholesterol and high triglycerides in statin-treated coronary men with low density lipoproteincholesterol <70 mg/dl. Am J Cardiol 5: 636-641, 2012.
28. Santamarina-Fojo S, Hoeg JM, Assmann G, et al: Lecithin Cholesterol Acyltransferase Deficiency and Fish Eye Disease. In: The Metabolic and MolecularBases of Inherited Diseases. Scriver CR, Beaudet al, Sly WS, Valle D (eds). McGraw-Hill Publishing, New York, pp2817-2833, 2001.

29. Rader DJ, Ikewaki K, Duverger N, et al: Markedly accelerated catabolism of apolipoprotein A-II (ApoA-II) and high density lipoproteins containing ApoA-II in classic lecithin: cholesterol acyltransferase deficiency and fish-eye disease. J Clin Invest 93: 321-330, 1994.

30. Kelso GJ, Stuart WD, Richter RJ, et al: Apolipoprotein J is associated with paraoxonase in human plasma. Biochemistry 33 : 832-839, 1994

31. Mackness MI, Arrol S and Durrington PN: Paraoxonase prevents accumulation of lipoperoxides in low-density lipoprotein. FEBS Lett 286: 152-154, 1991.

32. Watson AD, Berliner JA, Hama SY, et al: Protective effect of high density lipoprotein associated paraoxonase. Inhibition of the biological activity of minimally oxidized low density lipoprotein. J Clin Invest 96: 2882-2891, 1995.

33. Mackness MI, Walker CH and Carlson LA: Low A-esterase activity in serum of patients with fish-eye disease. Clin Chem 33: 587-588, 1987.

34. Huang Y, von Eckardstein A, Wu S, et al: A plasma lipoprotein containing only apolipoprotein $\mathrm{E}$ and with gamma mobility on electrophoresis releases cholesterol from cells. Proc Natl Acad Sci USA 91: 1834-1838, 1994.

35. Durrington PN, Mackness B and Mackness MI: The hunt for nutritional and pharmacological modulators of paraoxonase. Arterioscler Thromb Vasc Biol 22: 1248-1250, 2002.

36. Ferré N, Camps J, Fernández-Ballart J, et al: Regulation of serum paraoxonase activity by genetic, nutritional, and lifestyle factors in the general population. Clin Chem 49: 1491-1497, 2003

37. Calabresi L, Favari E, Moleri E, et al: Functional LCAT is not required for macrophage cholesterol efflux to human serum. Atherosclerosis 204: 141-146, 2009.

38. Nishiwaki M,IkewakiK,Bader G, et al:Human lecithin:cholesterol acyltransferase deficiency: in vivo kinetics of low-density lipoprotein and lipoprotein-X. Arterioscler Thromb Vasc Biol 26: 1370-1375, 2006

39. Savel J, Lafitte M, Pucheu Y, et al: Very low levels of HDL cholesterol and atherosclerosis, a variable relationship-a review of LCAT deficiency. Vasc Health Risk Manag 8: 357-361, 2012.

40. Duivenvoorden R, Holleboom AG, van den Bogaard B, et al: Carriers of lecithin cholesterol acyltransferase gene mutations have accelerated atherogenesis as assessed by carotid 3.0-T magnetic resonance imaging. J Am Coll Cardiol 58: 2481-2487, 2011.

41. El Harchaoui K, Arsenault BJ, Franssen R, et al: High-density lipoprotein particle size and concentration and coronary risk. Ann Intern Med 150: 84-93, 2009.

42. Syvänne M, Castro G, Dengremont C, et al: Cholesterol efflux from Fu5AH hepatoma cells induced by plasma of subjects with or without coronary artery disease and non-insulin-dependent diabetes: importance of LpA-I:A-II particles and phospholipid transfer protein. Atherosclerosis 127: 245-253, 1996. 